\title{
473565 - ANESTHETIC CONSIDERATIONS FOR EXTRACRANIAL TO INTRACRANIAL BYPASS (EC-IC) SURGERY: CONTROL OF BLOOD PRESSURE
}

\author{
Amit Prakash, MD, FRCA, Pirjo Manninen, MD FRCPC, Lakshmi \\ Venkatraghavan, MD, FRCA \\ Department of Anesthesia, Toronto Western Hospital, Toronto, ON, Canada
}

Introduction: EC-IC is a surgical procedure for the treatment and/or prevention of cerebral ischemia in patients with Moya Moya disease, complex cerebral aneurysms and stroke. Perioperatively there is a need for hemodynamic manipulations for cerebral preservation, and for the prevention of bleeding, anastomosis dehiscence and postoperative re-perfusion syndrome. The purpose of this study was to review the anesthetic management with respect to the perioperative control of blood pressure in patients undergoing EC-IC.

Methods: Following IRB approval the medical records of all patients who had an EC-IC (Jan 2001 to Oct 2006) were retrospectively reviewed. Information obtained included demographics, reason for EC-IC, anesthetic management, blood pressure levels, use of vasoactive agents intra and postoperatively, complications and outcome.

Results: A total of 56 procedures were performed, but due to incomplete data only 40 patients were included in this analysis. Patients were classified according to their medical condition for EC-IC into three groups: Moya Moya, cerebral aneurysms and stroke. Results for demographics and blood pressure are in the Table. None of the patients required augmentation of blood pressure during cross clamping of an artery when the anastomosis was performed. However control of blood pressure (induced hypotension) was used in $68 \%$ of all patients, and most frequently in the aneurysm group. Labetalol was the most commonly used agent. Complications are shown in table. A neurological deficit occurred in $17 \%(n=7)$ of all patients. In the aneurysm group 4 of the deficits were transient in nature.

Discussion: Our results highlight the importance of tight blood pressure control perioperatively during ECIC. However, there was one patient with a major intracranial bleed despite blood pressure control. Previous studies have shown that uncontrolled hypertension was the most common reason for ICU admissions postoperatively. (1) Other complications reported include anastomosis dehiscence and re-perfusion syndrome, though in our small sample size we did not find this.

References: 1 . Neurosurgery 1989; 25:618-28, 2. Anesth Analg 1997; 85: 1060-5

Results for demographics, blood pressure control and complications 


\begin{tabular}{|c|c|c|c|}
\hline & $\begin{array}{c}\text { Moya Moya } \\
\mathrm{N}=20\end{array}$ & $\begin{array}{c}\text { Cerebral Aneurysm } \\
\mathrm{N}=12\end{array}$ & $\begin{array}{c}\text { Stroke } \\
\mathrm{N}=8\end{array}$ \\
\hline Age (yr) & $45.3 \pm 15.9$ & $45.6 \pm 15.5$ & $48.1 \pm 14.4$ \\
\hline Sex (M:F) & $1: 4$ & $1: 3$ & $7: 1$ \\
\hline Blood pressure manipulation required & $40 \%(\mathrm{n}=8)$ & $100 \%(\mathrm{n}=12)$ & $88 \%(\mathrm{n}=7)$ \\
\hline Intraoperative MAP & $99 \pm 6$ & $88 \pm 37$ & $99 \pm 10$ \\
\hline PACU MAP & $104 \pm 15$ & $100 \pm 12$ & $112 \pm 19$ \\
\hline Drugs used intraoperatively and postoperatively & $\mathrm{N}=4$ \\
\hline Labetalol & $\mathrm{N}=8$ & $\mathrm{~N}=12$ & $\mathrm{~N}=1$ \\
\hline SNP & $\mathrm{N}=1$ & $\mathrm{~N}=4$ & $\mathrm{~N}=3$ \\
\hline Other & $\mathrm{N}=3$ & $\mathrm{~N}=6$ & $13 \%(\mathrm{n}=1)$ \\
\hline Neurological & \multicolumn{5}{|c|}{$5 \%$} & 0 \\
\hline Intracranial bleed & $5 \%(\mathrm{n}=1)$ & $33 \%(\mathrm{n}=5)$ & 0 \\
\hline Myocardial infarction & 0 & $8 \%(\mathrm{n}=1)$ & 0 \\
\hline
\end{tabular}

$\mathrm{MAP}=$ mean arterial pressure, $\mathrm{SNP}=$ sodium nitroprusside, Other = nitroglycerine, esmolol, hydralazine 